\title{
Maternal Risk Factors and Short Term Outcome of Prematurity: A Descriptive Study at a Secondary Care Hospital
}

\author{
Heeramani Lohana1, Shakeel Ahmed ${ }^{1,2 *}$, Nigar Jabeen1', Farida Kareem1, Sarwat Urooj1, \\ Ayesha Ahmed ${ }^{3}$ \\ ${ }^{1}$ Department of Paediatrics \& Child Health, Aga Khan University Hospital, Karachi, Pakistan \\ ${ }^{2}$ Department of Paediatrics, Bahria University Medical \& Dental College, Karachi, Pakistan \\ ${ }^{3}$ Department of Paediatrics, Dow University of Health Sciences, Karachi, Pakistan \\ Email: ^shakeel.ahmed@aku.edu
}

How to cite this paper: Lohana, $\mathrm{H}$., Ahmed, S., Jabeen, N., Kareem, F., Urooj, S. and Ahmed, A. (2020) Maternal Risk Factors and Short Term Outcome of Prematurity: A Descriptive Study at a Secondary Care Hospital. Open Journal of Pediatrics, 10, 486-492.

https://doi.org/10.4236/ojped.2020.103049

Received: March 30, 2020

Accepted: September 5, 2020

Published: September 8, 2020

Copyright $\odot 2020$ by author(s) and Scientific Research Publishing Inc. This work is licensed under the Creative Commons Attribution International License (CC BY 4.0).

http://creativecommons.org/licenses/by/4.0/

(c) (i) Open Access

\begin{abstract}
Background: Approximately 15 million babies are born premature (before 37 weeks of gestation) and 1 million babies die due to prematurity complications every year. Less is known about risk factors of prematurity in middle and low-income countries. The prevalence of prematurity ranges from $5 \%-18 \%$. Objective: To determine the prevalence of premature births and to assess the rate of survival, along with the morbidity, among preterm newborns. Furthermore, to document our experience with different gestational age groups of preterm births; and to analyze the association among these strata and their clinical outcomes. Study Design: A descriptive study. Place and Duration of Study: The Aga Khan Maternal and Childcare Centre Hyderabad, Pakistan, from $1^{\text {st }}$ January 2017 to $31^{\text {st }}$ December 2018. Methodology: All pregnant women registered at the obstetric clinic before 24 weeks of gestation having at least three subsequent visits at the same clinic were included in the study. The women who were lost to follow up before completing three visits were excluded from the study. All un-booked women were also excluded from the study. Demographic profile was recorded including maternal age, parity, no of visits at the clinic, gestational age, mode of delivery, birth weight and pregnancy outcome. Newborns were subsequently followed at nursery or well-baby till discharge. Further subgroups were made for gestational age to assess the frequency of various morbidities in each group. Results: One thousand and ninety-one (1091) women were included in the study period that fulfilled the inclusion criteria. Two pregnancies were terminated before 24 weeks due to major congenital malformations. The prevalence of prematurity was recorded as $13.4 \%(146 / 1089)$. Perinatal mortality rate (no of still-
\end{abstract}


births plus the number of early neonatal death/1000 live birth) was 17 (15.6/1000 live births) out of them, 12 were still births and 5 were early neonatal death. Out of the total preterm babies born, 59.5\% (87/146) were admitted to the nursery. In the study group $(2 \% / 3146)$ were extreme preterm, while $7.5 \%$ were severe preterm (11/146). Moderate preterm was $11.6 \%$ (17/146) and the majority were late preterm accounting for $78.7 \%(115 / 146)$. Though the incidence of birth asphyxia were noted more in late preterm babies i.e. 10 as the number of these babies are also high in our study but the overall percentage was low (8.7\%) as compared with the babies of extreme prematurity (100\%) and moderate late prematurity (23.5\%) respectively. In pregnancy outcome, 12 were still births in which six (50\%) were in the late preterm group. Total of 17 newborns suffered from birth asphyxia in which ten newborns (58.8\%) were in late preterm group. Overall, it was noted that the decreasing gestational age was directly correlated to morbidity and mortality. Conclusion: Among the different strata, the late preterm group has been observed to be associated with greater morbidity and mortality. Prior awareness of the morbidities associated with late preterm babies is helpful for the health care providers to anticipate and manage potential complications in preterm infants.

\section{Keywords}

Preterm Birth, Risk Factors, Neonatal Morbidity

\section{Introduction}

Preterm birth poses a wide range of perinatal challenges and is closely related to perinatal mortality and morbidity. The American Academy of Pediatrics and the American College of Obstetrician and Gynecologists define a preterm infant as one who is born before the 37th week (259th days) of pregnancy, counting from the first day of last menstrual period [1]. The frequency of preterm births is about $12 \%-13 \%$ in the USA and 5\% - 9\% in many other developed countries; however, the rate of preterm birth has increased in many locations [2]. Developing countries, especially those in Africa and southern Asia, incur the highest-burden in terms of absolute numbers, although a high rate is also observed in North America. In developing countries, accurate and complete population data and medical records usually do not exist [3], particularly, in South East Asia, where limited work has been done so far, and only a few studies have been published.

Therefore, this study aims to determine the prevalence of preterm birth and to assess the rate of survival, along with the morbidity among preterm newborns. Furthermore, our goal was to document our experience within different gestational age group preterm births and to analyze the association among this strata and their clinical outcomes. 


\section{Methodology}

We conducted a retrospective descriptive study through a medical record review at the Department of Pediatrics, The Aga Khan Maternal and Child Care Centre Hyderabad over a period of two years (from $1^{\text {st }}$ January 2017 to $31^{\text {st }}$ December 2018) in collaboration with the Department of Obstetrics. The Aga Khan Maternal and Child Care Centre is a secondary care level Hospital with a well-equipped nursery, only falling short of a ventilator facility. All pregnant women were registered at the Obstetric clinic before 24 weeks of gestation, having at least three subsequent visits at the same clinic, were included in the study. The women who had lost follow up before completing three visits were excluded from the study. All un-booked women were also excluded from the study.

The study got the ethical review exemption from the institutional ethical review committee.

Demographical profile was recorded by Principal Investigator and medical officer from medical records of patients including maternal age, parity, number of visits at the clinic, gestational age, mode of delivery, birth weight, and pregnancy outcome. Newborns who were further followed at the nursery or well-baby clinic till discharge. Further subgroups were made for gestational age to assess the frequency of various morbidities in each group. Gestational age was classified into four groups i.e. extremely preterm (born before 28 weeks of gestation), severe preterm (born between 28 to $<32$ weeks of gestation), moderate preterm (born at 32 to $<34$ weeks of gestation) and late preterm (born between 34 to $<37$ weeks of gestation) as described in the literature.

\section{Data Management}

Data was extracted from medical records files and were entered into the MS Excel sheet in predefined variables of interest sheet and responses were coded. Data was also analyzed in MS Excel and data was presented in frequencies and percentages.

\section{Results}

During the study period, three thousand two hundred and five (3205) women were registered at the Obstetrical clinic. Out of these, one thousand and ninety-one (1091) women were included in the study period that fulfilled the inclusion criteria. Two pregnancies were terminated before 24 weeks due to major congenital malformations. The prevalence of prematurity was recorded as $13.4 \%$ (146/1089). Perinatal mortality rate (number of still births plus the number of early neonate death (ENND) per1000 live birth) was 15.6\% (12 still births +5 ENND).

Among the live births, 2\% (3/146) were extreme preterm, 7.5\% (11/146) were severe preterm, $11.6 \%(17 / 146)$ were moderate preterm and the majority was late preterm, accounting for $78.7 \%(115 / 146)$ as described in Table 1. 
Among the different strata, the late preterm group has been observed to be associated with increased morbidity and mortality (Table 2). Out of the total 17 $(11.6 \%)$ cases of birth asphyxia, 10 cases were reported in the late preterm group vs $4(23.5 \%)$ in the severe preterm group, while all 3 of the reported cases of extreme preterm had birth asphyxia. However, it is interesting to note that although the number of babies who suffered from birth asphyxia in the late preterm group is the highest, the percentage is the lowest. Similarly, a total of 30 (20.5\%) children had neonatal jaundice (NNJ), among whom 20 (17.4\%) belonged to the late preterm group while $7(41.2 \%)$ were from the moderate preterm and $3(27.3 \%)$ were the severe preterm group. Furthermore, $10(6.8 \%)$ cases developed respiratory distress syndrome (RDS), among which 7 (6.1\%) were from the late preterm group.

Overall, 8\% (12/146) of the cases resulted in Intra-uterine death (IUD), among which the majority of the cases were from the late preterm group as their overall numbers are also high, as shown in Table 3.

Of the 134 live births, 87 were delivered via emergency C-sections (EM LSCS), whereas 42 were spontaneous vaginal deliveries (SVD) and only 19 were delivered via elective C-sections (EL LSCS), as given in Table 4. 89 live-born babies required admission in the nursery (see Table 4).

Table 1. Preterm strata based on the gestational age.

\begin{tabular}{cccccc}
\hline & $\begin{array}{c}<28 \text { Weeks } \\
\text { Extreme } \\
\text { Prematurity }\end{array}$ & $\begin{array}{c}28-<32 \text { Weeks } \\
\text { Severe } \\
\text { Prematurity }\end{array}$ & $\begin{array}{c}32-33 \text { Weeks } \\
\text { Moderate } \\
\text { Prematurity }\end{array}$ & $\begin{array}{c}>33 \text { to }<37 \text { Weeks } \\
\text { Late } \\
\text { Prematurity }\end{array}$ & Total \\
\hline Gestational & $1\left(\mathrm{~F}^{*}\right)$ & $4(\mathrm{~F})$ & $12(\mathrm{~F})$ & $48(\mathrm{~F})$ & 65 \\
Total & $2\left(\mathrm{M}^{* *}\right)$ & $7(\mathrm{M})$ & $3(\mathrm{M})$ & $67(\mathrm{M})$ & 81 \\
\hline
\end{tabular}

${ }^{*}$ Female; ${ }^{* *}$ Male.

Table 2. Associated morbidities among various strata.

\begin{tabular}{|c|c|c|c|c|c|}
\hline & $\begin{array}{l}<28 \text { Weeks } \\
\text { Extreme } \\
\text { Prematurity } \\
\qquad(\mathrm{n}=3)\end{array}$ & $\begin{array}{c}28-<32 \text { Weeks } \\
\text { Severe } \\
\text { Prematurity } \\
(\mathrm{n}=11)\end{array}$ & $\begin{array}{c}32 \text { - } 33 \text { Weeks } \\
\text { Moderate } \\
\text { Prematurity } \\
(\mathrm{n}=17)\end{array}$ & $\begin{array}{c}>33 \text { to }<37 \text { Weeks } \\
\text { Late } \\
\text { Prematurity } \\
(\mathrm{n}=115)\end{array}$ & Total \\
\hline Birth Asphyxia & $3(100 \%)$ & & $4(23.5 \%)$ & $10(8.75 \%)$ & $17(11.6 \%)$ \\
\hline NNJ & & $3(27.3 \%)$ & $7(41.2 \%)$ & $20(17.4 \%)$ & $30(20.5 \%)$ \\
\hline RDS & $2(66.7 \%)$ & & $1(5.9 \%)$ & $7(6.1 \%)$ & $10(6.8 \%)$ \\
\hline $\begin{array}{l}\text { Anemia of } \\
\text { prematurity }\end{array}$ & & $1(9.1 \%)$ & & $2(1.8 \%)$ & $3(2.1 \%)$ \\
\hline $\begin{array}{c}\text { Apnea of } \\
\text { prematurity }\end{array}$ & $1(33.3 \%)$ & $1(9.1 \%)$ & $1(5.9 \%)$ & $1(0.9 \%)$ & $4(2.8 \%)$ \\
\hline Hypoglycemia & & $2(18.2 \%)$ & $2(11.8 \%)$ & $3(2.6 \%)$ & $7(4.8 \%)$ \\
\hline Hypocalcemia & & $1(9.1 \%)$ & $6(35.3 \%)$ & $10(8.7 \%)$ & $17(11.6 \%)$ \\
\hline
\end{tabular}


Table 3. Associated mortality among various strata.

\begin{tabular}{cccccc}
\hline & $\begin{array}{c}<28 \text { Weeks } \\
\text { Extreme } \\
\text { Prematurity }\end{array}$ & $\begin{array}{c}28-<32 \text { Weeks } \\
\text { Severe } \\
\text { Prematurity }\end{array}$ & $\begin{array}{c}32-33 \text { Weeks } \\
\text { Moderate } \\
\text { Prematurity }\end{array}$ & $\begin{array}{c}>33 \text { to }<37 \text { Weeks } \\
\text { Late } \\
\text { Prematurity }\end{array}$ & Total \\
\hline IUD & 1 & 3 & 2 & 6 & 12 \\
ALIVE & 4 & 8 & 13 & 109 & 134 \\
\hline
\end{tabular}

Table 4. Mode of Delivery and nursery requirement among the various strata.

\begin{tabular}{cccccc}
\hline & $\begin{array}{c}<28 \text { Weeks } \\
\text { Extreme } \\
\text { Prematurity }\end{array}$ & $\begin{array}{c}28-<32 \text { Weeks } \\
\text { Severe } \\
\text { Prematurity }\end{array}$ & $\begin{array}{c}32-33 \text { Weeks } \\
\text { Moderate } \\
\text { Prematurity }\end{array}$ & $\begin{array}{c}>33 \text { to }<37 \text { Weeks } \\
\text { Late } \\
\text { Prematurity }\end{array}$ & Total \\
\hline Em LSCS* & 4 & 3 & 11 & 69 & 87 \\
EL LSCS* & & & & 19 & 19 \\
SVD $^{* *}$ & 3 & 8 & 4 & 27 & 42 \\
Nursery & 4 & 8 & 12 & 63 & 87 \\
Admission & 4 & & & & \\
\hline
\end{tabular}

${ }^{*}$ Lower cesarean section; ${ }^{* *}$ Spontaneous vaginal delivery.

\section{Discussion}

Our study showed the prevalence of preterm births to be $13.4 \%$, with the majority being late preterm. Consistent with our data, the rate of preterm birth ranges from $5 \%$ to $18 \%$ of babies born globally, and over $60 \%$ of preterm births occur in Africa and South Asia [4]. The mortality rate among these premature births was as high as $15.6 \%$ ( 12 still births +5 ENND). Furthermore, a study conducted by Stacy Beck et al. demonstrated that of the 12.9 million preterm births in 2005, 10.9 million were found to be in Africa and Asia, with Europe and North America contributing to only about 0.5 million of the preterm births [3]. Kramer et al. showed that late-preterm infants have a mortality rate that is three times greater than term infants, with the highest risk occurring during the neonatal period [5]. Similarly, a study conducted in Utah compared the mortality rates of babies born at 40 weeks of gestation with those born prior to that, drawing the conclusion that both infant and neonatal mortality rates were considerably higher for the babies who were born before term [6]. Determination of gestational age is important to assess risks for morbidity and mortality in neonates. In our study, stratification of these children based on gestational age showed that the late preterm group is the most vulnerable in terms of both neonatal morbidity and mortality; a finding mirrored by a study done in the United States which claimed that as compared to term infants, late preterm infants had a much higher mortality rate throughout their period of infancy [7]. This result is further supported by research performed by Brain M. D'Onofrio, et al. which revealed a significant decrease in the infant mortality rate with increased gestational age [8].

\section{Conclusion}

In developing countries, difficulties are faced with the collection and analysis of 
population-based data, due to the limited provision of antenatal and perinatal care. Registration of births is incomplete and information is lacking on gestational age, especially outside hospital settings [9]. In low middle income countries like Pakistan, where the resources to help counter these statistics are scarce, a large impact can be made in decreasing neonatal morbidity and mortality in the late preterm group by providing meticulous care [10].

\section{Limitations}

As it was a retrospective record review study at secondary care hospital, so we cannot generalize these findings but the results of this study have added in evidence generation.

\section{Data Availability}

Data of the study will be available on request.

\section{Funding Statement}

Study does not need any internal or external funding.

\section{Conflicts of Interest}

The authors declare no conflicts of interest regarding the publication of this paper.

\section{References}

[1] American Academy of Pediatrics and the American College of Obstetricians and Gynecologists (2007) Guidelines for Perinatal Care. 6th Edition, Elk Grove Village, Washington, DC.

[2] Goldenberg, R.L., Culhane, J.F., Iams, J.D. and Romero, R. (2008) Epidemiology and Causes of Preterm Birth. The Lancet, 371, 75-84. https://doi.org/10.1016/S0140-6736(08)60074-4

[3] Beck, S., Wojdyla, D., Say, L., Betran, A.P., Merialdi, M., Requejo, J.H., et al. (2010) The Worldwide Incidence of Preterm Birth: A Systematic Review of Maternal Mortality and Morbidity. The Bulletin of World Health Organization, 88, 31-38. https://doi.org/10.2471/BLT.08.062554

[4] Blencowe, H., Cousens, S., Oestergaard, M.Z., Chou, D., Moller, A.B., Narwal, R., et al. (2012) National, Regional, and Worldwide Estimates of Preterm Birth Rates in the Year 2010 with Time Trends since 1990 for Selected Countries: A Systematic Analysis and Implications. The Lancet, 379, 2162-2172. https://doi.org/10.1016/S0140-6736(12)60820-4

[5] Kramer, M.S., Demissie, K., Yang, H., Platt, R.W., Sauve, R. and Liston, R. (2000) The Contribution of Mild and Moderate Preterm Birth to Infant Mortality. JAMA, 284, 843-849. https://doi.org/10.1001/jama.284.7.843

[6] Young, P.C., Glasgow, T.S., Li, X., Guest-Warnick, G. and Stoddard, G. (2007) Mortality of Late-Preterm (Near-Term) Newborns in Utah. Pediatrics, 119, e659-e665. https://doi.org/10.1542/peds.2006-2486

[7] Tomashek, K.M., Shapiro-Mendoza, C.K., Davidoff, M.J. and Petrini, J.R. (2007) 
Differences in Mortality between Late-Preterm and Term Singleton Infants in the United States, 1995-2002. The Journal of Pediatrics, 151, 450-456.E1.

https://doi.org/10.1016/j.jpeds.2007.05.002

[8] D’Onofrio, B.M., Class, Q.A., Rickert, M.E., Larsson, H., Langstrom, N. and Lichtenstein, P. (2013) Preterm Birth and Mortality and Morbidity: A Population-Based Quasi-Experimental Study. JAMA Psychiatry, 70, 1231-1240.

https://doi.org/10.1001/jamapsychiatry.2013.2107

[9] Kaltreider, D.F. and Kohl, S. (1980) Epidemiology of Preterm Delivery. Clinical Obstetrics and Gynecology, 23, 17-31.

https://doi.org/10.1097/00003081-198003000-00005

[10] Haroon, A., Ali, S.R., Ahmed, S. and Maheen, H. (2014) Short-Term Neonatal Outcome in Late Preterm vs. Term Infants. Journal of the College of Physicians and Surgeons Pakistan, 24, 34-38. 